\title{
LAMINAÇÃO TERMOMECÂNICA DE UM AÇO MICROLIGADO AO NIÓBIO EM UM LAMINADOR DE TIRAS A QUENTE, COM CADEIRA STECKEL*
}

João Júnio Pereira Lino ${ }^{1}$ Jorge Adam Cleto Cohn² Edson Hugo Rossi ${ }^{3}$ Altair Lúcio de Souza 4 Geraldo Lúcio de Faria ${ }^{5}$ Willy Schuwarten Júnior ${ }^{6}$

\section{Resumo}

Este trabalho tem como objetivo demonstrar a aplicação das técnicas de laminação termomecânica de aços microligados para obtenção de propriedades mecânicas elevadas em um laminador Steckel. O processamento de um aço com composição química favorável à obtenção de propriedades mecânicas compatíveis com o grau X60 especificado na norma API $5 \mathrm{~L}$ é demonstrado. Foram alcançados limites de escoamento a $0,5 \%$ de deformação e a resistência à tração mínimos de $473 \mathrm{MPa}$ e $549 \mathrm{MPa}$ respectivamente, alongamento médio de $38 \%$, razão elástica em $86 \%$ e temperatura de transição dúctil frágil em torno de $-50^{\circ} \mathrm{C}$ atendendo às especificações da norma.

Palavras-chave: Laminador steckel; Laminação termomecânica; Propriedades mecânicas; Aço microligado; APII.

\section{THERMOMECHANICAL ROLLING OF A NIOBIUM MICROALLOYED STEEL IN A HOT STRIP MILL, STECKEL MILL STAND}

\section{Abstract}

This paper has the objective to demonstrate the thermomechanical rolling techniques for microalloyed steel processing in order to obtain high level of mechanical properties in a Steckel Mill. The processing of a steel with chemical composition favorable to achieve compatible mechanical properties to X60 grade steel specified by API 5L standard is demonstrated. Were achieved minimum yield strength at $0,5 \%$ strain and tensile strength of $473 \mathrm{MPa}$ and $549 \mathrm{MPa}$ respectively, mean elongation of $38 \%, Y S / U T S$ ratio of $86 \%$ and ductile fragile temperature around $-50^{\circ} \mathrm{C}$ fitting the standard requirements.

Keywords: Steckel mill; Thermo mechanical rolling; Mechanical properties; Micro alloyed steel; API.

1 Engenheiro Mecânico, Mestrando em Metalurgia, Assessor Técnico, Laminação de Tiras a Quente, Gerdau Ouro Branco, Ouro Branco, Minas Gerais, Brasil.

2 Engenheiro Metalurgista, Mestre em Metalurgia, Consultor Técnico, Pesquisa a Desenvolvimento Aços Planos, Gerdau Ouro Branco, Ouro Branco, Minas Gerais, Brasil.

3 Engenheiro Metalurgista, Mestre em Metalurgia, Consultor Técnico, Laminação de Tiras a Quente, Gerdau Ouro Branco, Ouro Branco, Minas Gerais, Brasil.

4 Engenheiro Metalurgista, Mestre em Metalurgia, Assessor Técnico, Laminação de Tiras a Quente, Gerdau Ouro Branco, Ouro Branco, Minas Gerais, Brasil.

5 Físico, Dr. em Engenharia de Materiais, Professor, Departamento de Engenharia Metalúrgica e de Materiais, Universidade Federal de Ouro Preto, Ouro Preto, Minas Gerais e Brasil.

6 Engenheiro Mecânico, Mestre em Metalurgia, Gerente da Laminação de Tiras a Quente, Gerdau Ouro Branco, Ouro Branco, Minas Gerais, Brasil. 


\section{INTRODUÇÃO}

A indústria do aço tem demandado cada vez mais aços de alta resistência mecânica, elevada tenacidade a baixas temperaturas, ductilidade e boa soldabilidade especialmente para aços destinados a fabricação de dutos de grande diâmetro para transporte de hidrocarbonetos [1]. Para aplicações especiais em locais remotos e ambientes agressivos, são necessárias propriedades adicionais tais como resistência a trinca induzida por hidrogênio (HIC), contra a corrosão sob tensão e resistência à fadiga [2].

A necessidade de utilização de aços de maior resistência mecânica e tenacidade é reforçada também pela sua viabilidade econômica, uma vez que custos menores para transporte, fabricação e instalação são conseguidos.

A adição de microligantes associada à laminação termomecânica tem a principal função de promover o refino de grãos e da microestrutura do aço de forma a se obter resistência mecânica e tenacidade melhoradas no produto como laminado a quente. Os microligantes, tais como nióbio, titânio e vanádio têm grande afinidade com o carbono e o nitrogênio formando nitretos, carbonetos e carbonitretos que precipitados na matriz alteram as propriedades mecânicas do aço. Os precipitados agem de forma a impedir a movimentação do contorno do grão e consequentemente inibindo seu crescimento após os passes de laminação [1]. A temperatura na qual a inibição da recristalização ocorre é denominada Temperatura de Não Recristalização (Tnr).

A deformação sucessiva do grão austenítico a temperaturas abaixo da Tnr promove um empanquecamento do grão. O achatamento destes grãos e as bandas de deslizamento geradas levam a uma maior quantidade de sítios para nucleação de grãos ferríticos.

A utilização do nióbio apresenta vantagens em relação aos outros microligantes, pois tem elevada afinidade com o carbono e o nitrogênio, solubilidade necessária na austenita, grande potencial para formação de precipitados na austenita e ferrita e baixa afinidade com o oxigênio [1]. É destacada a sua capacidade de elevar a Tnr a valores muito altos possibilitando melhores condições para a laminação termomecânica e alcance da microestrutura desejada [3].

Para que seja alcançado o refino de grão adequado, a liga do aço e o processo devem ser cuidadosamente definidos. Alguns parâmetros chave para o sucesso da laminação do aço HTP (High Temperature Processing) são [3]:

- Temperatura de reaquecimento adequada para promoção da solubilização dos microligantes;

- Espessura de espera maior que 3,5 vezes a espessura final requerida;

- Alta temperatura de acabamento para promover uma maior taxa de resfriamento;

- Temperatura ao final do resfriamento acelerado baixa o bastante para formação de microestruturas favoráveis.

\subsection{Efeitos dos elementos microligantes}

A adição de elementos químicos contribuem para o refinamento dos grãos ferríticos do aço. Elementos tais como nióbio, titânio, molibdênio e vanádio têm grande afinidade com o carbono e o nitrogênio formando nitretos, carbonetos e carbonitretos que precipitados na matriz durante a laminação interferem na microestrutura do aço. Os precipitados agem de forma a impedir a movimentação do contorno do grão e 
consequentemente inibindo seu crescimento após os passes de laminação [1]. Estes elementos são denominados microligantes devido à baixa a relação entre a baixa adição dos mesmos e o benefício conseguido no endurecimento do aço.

O poder do microligante encontra-se na capacidade de geração de forças para o impedimento da movimentação dos defeitos cristalinos que gerariam os fenômenos de recristalização e crescimento do grão austenítico. À habilidade de reter o deslocamento do contorno de grãos denomina-se mecanismo de arraste de soluto [1]. Cada um dos elementos microligantes, apesar da função principal de refinamento de grãos, têm particularidades que devem ser levadas em consideração no planejamento da composição química e processamento aço.

A deformação sucessiva do grão austenítico a temperaturas abaixo da Tnr promove um empanquecamento do grão. O achatamento destes grãos resulta em uma área de contorno de grão muito maior relativamente e disponibilizando uma maior quantidade de sítios para nucleação de grãos ferríticos e com alto refinamento.

O parâmetro Sv é a relação entre o somatório da área e o somatório do volume total de contornos de grãos. Quão mais adequado o condicionamento da austenita antes do início da transformação da austenita mais elevado o parâmetro Sv. Este parâmetro corresponde à densidade de sítios para nucleação de ferrita por unidade volume [1]. Assim com altos valores de Sv consegue se um maior refinamento do grão ferrítico. A figura 1 ilustra a correlação do parâmetro Sv com o tamanho de grão ferrítico.

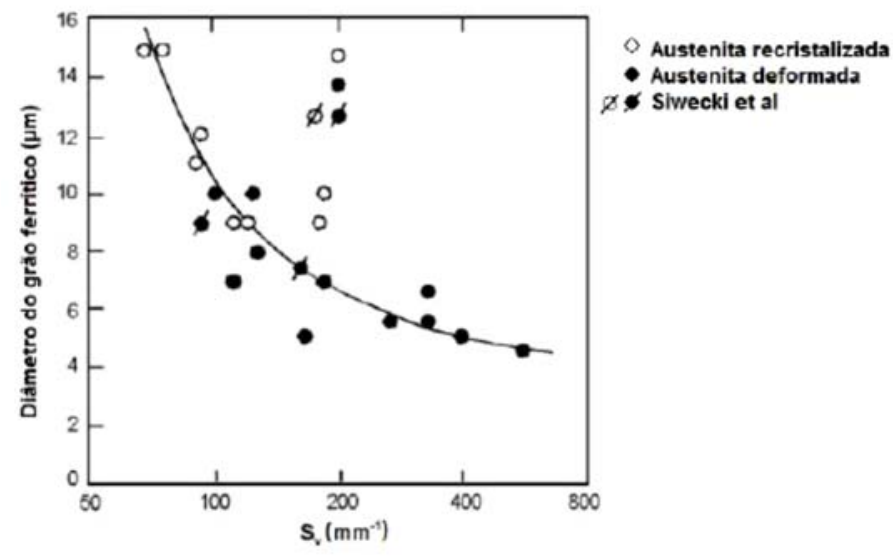

Figura 1. Tamanho de grão ferrítico obtido em função do parâmetro Sv [1]

A laminação controlada assim como o processo adequado de reaquecimento da placa para a dissolução do nióbio, o condicionamento da austenita durante, o empaquecamento do grão austenítico durante a laminação de acabamento, a transformação de fases após a laminação com eventual resfriamento acelerado e o efeito da precipitação a baixas temperaturas depois do bobinamento, são fatores para extrair o máximo dos fenômenos metalúrgicos envolvidos [4].

\subsection{O nióbio como elemento microligante}

O nióbio apresenta algumas características muito atrativas quando adicionado à liga. Ele tem elevada afinidade com o carbono e nitrogênio formando os carbonetos e carbonitretos de nióbio, alta solubilidade na austenita e baixa afinidade com o oxigênio [1]. Com a adição do nióbio pode ser obtida uma microestrutura mais refinada e o endurecimento por precipitação na matriz ferrítica, além do 
retardamento da recristalização da austenita, fator muito importante para a execução da laminação a quente.

A Figura 2 representa o efeito da adição do nióbio em comparação aos outros principais microligantes na temperatura de não recristalização (Tnr).

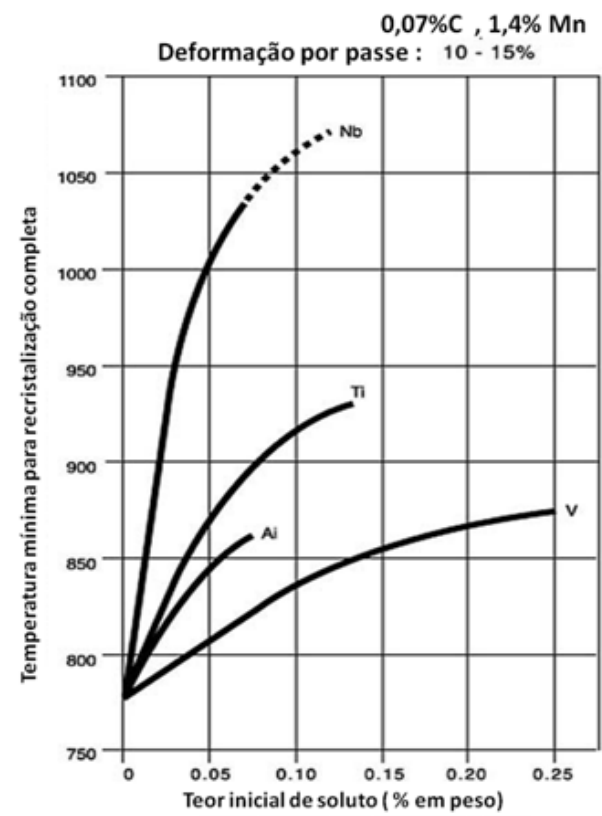

Figura 2. Efeito da adição do nióbio em comparação aos outros principais microligantes na Tnr. Adaptado de [5]

\subsection{Laminador de Tiras a Quente, com cadeira tipo Steckel da Gerdau}

O laminador de tiras a quente da Gerdau entrou em operação no mês de Outubro do ano de 2013 e desde então passou por grandes avanços no desenvolvimento do mix de produção. As dimensões de produtos que compõem o mix de produção do laminador da Gerdau são na espessura de $1,8 \mathrm{~mm}$ a $25,4 \mathrm{~mm}$, nas larguras de $850 \mathrm{~mm}$ a $2100 \mathrm{~mm}$. Na medida em que a espessura diminui e a largura aumenta, aumenta também a dificuldade no processamento [6].

Os laminadores Steckel representam as soluções econômicas para a produção de até 1.000.000 t de laminados a quente.

Estes também podem ser lucrativos quando usados para produzir aços carbono e aços especiais, quando a produção for limitada e os lotes de pedidos forem pequenos [6].

Quando se faz uma comparação com laminadores convencionais contínuos, o laminador Steckel tem como característica, tempo entre passes muito elevados, facilitando assim a ocorrência de recristalização em aços comuns e de baixo teor de nióbio. A laminação de aços microligados configura uma alternativa interessante para a produção de aços para fabricação de dutos e estruturais neste tipo de laminador [1].

\section{MATERIAIS E MÉTODOS}

Para o desenvolvimento deste trabalho, a laminação de um aço com composição química adequada para obtenção de um material compatível com o X60 especificado na norma API 5L, foi executada no Laminador de Tiras a Quente da 
Gerdau Ouro Branco, com cadeira tipo Steckel única para desbaste e acabamento. Foi planejada para a bobina a obtenção da espessura final de 9,50mm.

\subsection{Material}

Para a laminação experimental foram selecionadas 3 placas na espessura de $220 \mathrm{~mm}$ e largura de $900 \mathrm{~mm}$ produzidas na planta da Gerdau Ouro Branco. A composição química básica está representada na tabela 1 que consiste basicamente na pequena adição de $\mathrm{C}$, alto teor de $\mathrm{Mn}$ e adição de $\mathrm{Nb}$.

Tabela 1. Concentração de C, Mn, Nb e N na Placa (\% em peso)

\begin{tabular}{cccc}
\hline $\mathrm{C}$ & $\mathrm{Mn}$ & $\mathrm{Nb}$ & $\mathrm{N}(\mathrm{ppm})$ \\
\hline$<0,15$ & $<1,40$ & $<0,050$ & $<70$ \\
\hline
\end{tabular}

A composição química do aço estudado é adequada para obtenção de limite de escoamento (LE) acima de $415 \mathrm{MPa}$ nos ensaios de resistência à tração, correspondendo ao valor mínimo especificado para tubo do grau X60 da especificação API 5L [7].

\subsection{Processo de Reaquecimento da Placa}

Para o processo de reaquecimento e a solubilização completa do Nióbio, foram definidos os seguintes parâmetros:

- Temperatura de encharque e desenfornamento da placa em $1240^{\circ} \mathrm{C}$;

- Tempo mínimo de residência total de 4 horas;

- Cadência de laminação das placas anteriores em 10 minutos;

A temperatura de desenfornamento foi definida com base na equação (1) para solubilidade dos carbonitretos de nióbio proposta por Siciliano demonstrada abaixo [8].

$$
T=\frac{838[\mathrm{Mn}]^{0,246}-1730[\mathrm{Si}]^{0,594}-6440}{\log [\mathrm{Nb}] \times\left[C+\frac{12}{14} N\right]-2,26}-273
$$

\subsection{Laminação a Quente}

A estratégia de laminação teve como premissas, a aplicação de uma alta redução nos passes de desbaste objetivando uma redução de $40 \%$ no último passe antes da espera com o objetivo de se obter menor tamanho de grão austenítico; a espera para resfriamento em uma espessura a partir da qual era possível desenvolver alta deformação do grão austenítico abaixo da temperatura de não recristalização, e a laminação de acabamento no mínimo de passes possível [9].

Doug Stalheim propôs uma nova equação (2) para definição da temperatura de não recristalização (Tnr) aplicando um fator de $80 \%$ de eficiência sobre a equação de Boratto nos teores de $\mathrm{Nb}, \mathrm{Al}, \mathrm{V}, \mathrm{Ti}$ e $\mathrm{Si}$ com base em resultados práticos de laminação de aços microligados [10]. A equação (2) está descrita abaixo.

$$
\begin{aligned}
& \text { Tnr }=887+464 C+(6645 \times(0,80 N b)-644 \sqrt{0,80 N b})+(732 \times(0,80 \mathrm{~V})-230 \sqrt{0,80 V}) \\
& +890 \times(0,80 \mathrm{Ti})+363 \times(0,80 \mathrm{Al})-357 \times(0,80 \mathrm{Si})
\end{aligned}
$$


A temperatura de não recristalização calculada para o fim da espera no resfriamento foi estimada com base na equação descrita acima. Com base nas temperaturas calculadas foi definida a temperatura de $945^{\circ} \mathrm{C}$.

A espessura da espera foi definida com base na espessura final de laminação. Levando-se em consideração que a espessura final seria de $9,5 \mathrm{~mm}$ e que a espessura de espera deve ter uma relação de 3,5 vezes maior para que deformação seja o mais uniforme ao longo da espessura do passe, foi definida a espessura de patamar em $34 \mathrm{~mm}$.

A definição do tempo de espera na espessura de $34 \mathrm{~mm}$ foi feita pelo modelamento matemático do laminador considerando a previsão da temperatura no centro da espessura do esboço em comparação com a temperatura definida para o fim da espera. Os valores de temperatura medida são utilizados na adaptação dos cálculos efetuados pelo modelo.

A distribuição da redução planejada para cada passe está apresentada na Figura 3.

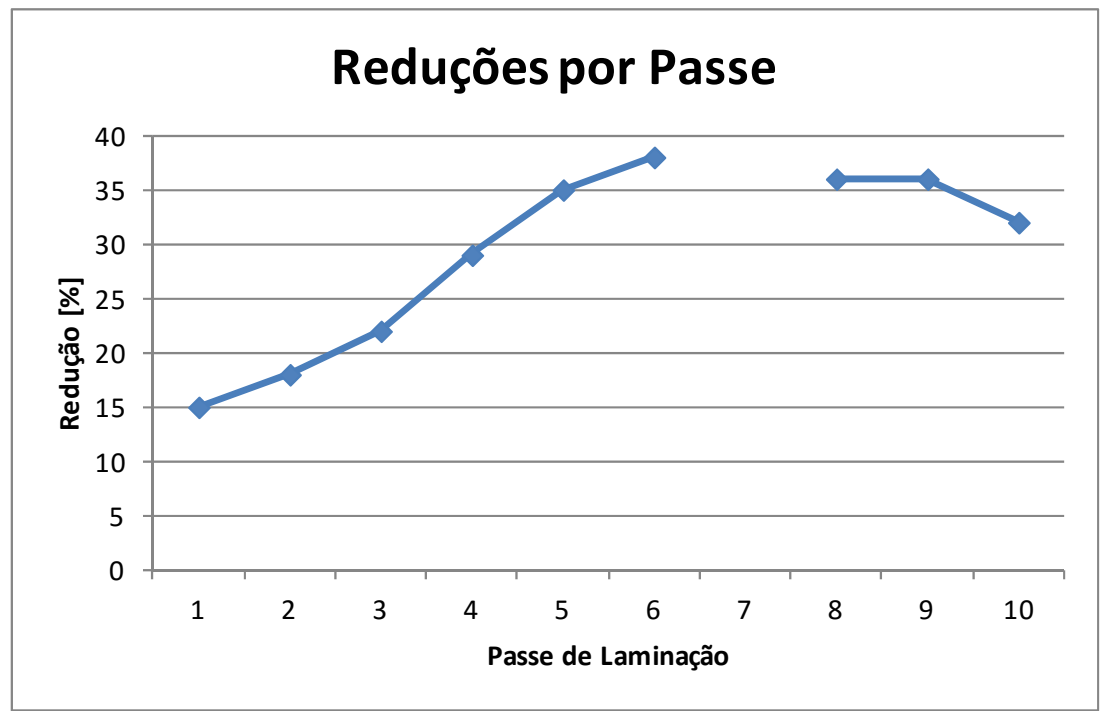

Figura 3. Reduções por passe executada

A temperatura após o último passe de acabamento foi objetivada para que estivesse acima da temperatura $\mathrm{Ar}_{3}$. A temperatura $\mathrm{Ar}_{3}$ para a composição química do material foi calculada com base na equação (3) proposta por Bai et al. descrita abaixo [11]. Com base nos resultados encontrados no cálculo foi definida como sendo $910^{\circ} \mathrm{C}$ devido ao efeito de as deformações acima e abaixo da Tnr causarem um aumento da temperatura $\mathrm{Ar}_{3}[12]$.

$$
\text { Ar3 }=910-310 C-80 M n-20 C u-15 C r-55 N i-80 M o+0,35(t h-8)
$$

\subsection{Resfriamento Acelerado}

Após a laminação do material foi projetado o resfriamento acelerado da bobina através do laminar cooling para auxiliar no refinamento de grãos. Foi objetivado o alcance da temperatura de bobinamento definida com alta taxa de resfriamento utilizando o máximo das zonas de resfriamento pesado e ajuste fino pelas zonas de resfriamento leve. 


\subsection{Ensaios Laboratoriais}

Foi planejada a retirada de amostras a partir da cauda do material laminado após resfriamento completo da bobina para ensaio mecânico de tração, tenacidade ao impacto, levantamento da curva de transição dúctil frágil e análise microestrutural.

Para os ensaios de tração, foram preparados os corpos de prova de acordo com a norma ASTM A370. Os corpos de prova foram retirados no sentido transversal da tira a $1 / 4$ da largura. Para os ensaios de tenacidade ao impacto foram utilizados corpos de prova subsize de acordo com a norma ASTM A370 [13].

O equipamento utilizado para o ensaio de tração foi uma máquina universal de ensaios Shimadzu modelo UH-F600kNI. Para os ensaios de tenacidade ao impacto e levantamento da temperatura de transição dúctil frágil foi utilizada uma máquina de pêndulo Zwick modelo PSW750.

Para metalografia, foram preparados corpos de prova na seção longitudinal e o ataque foi feito com a solução picral $4 \%$ seguido de nital $3 \%$.

\section{RESULTADOS E DISCUSSÃO}

\subsection{Processamento}

O processamento do material foi realizado conforme planejado. Os passes de laminação bem como as temperaturas de processamento foram cumpridos pelo modelamento matemático de alto desempenho equipado no laminador.

A temperatura de bobinamento objetivada foi conseguida ao longo do todo o comprimento da tira. A evolução da temperatura das tiras está apresentada esquematicamente na figura 4 onde o eixo $x$ é o tempo, o y temperatura e o $z o$ comprimento da tira. Obteve se sucesso aplicando a maior taxa de resfriamento no material.

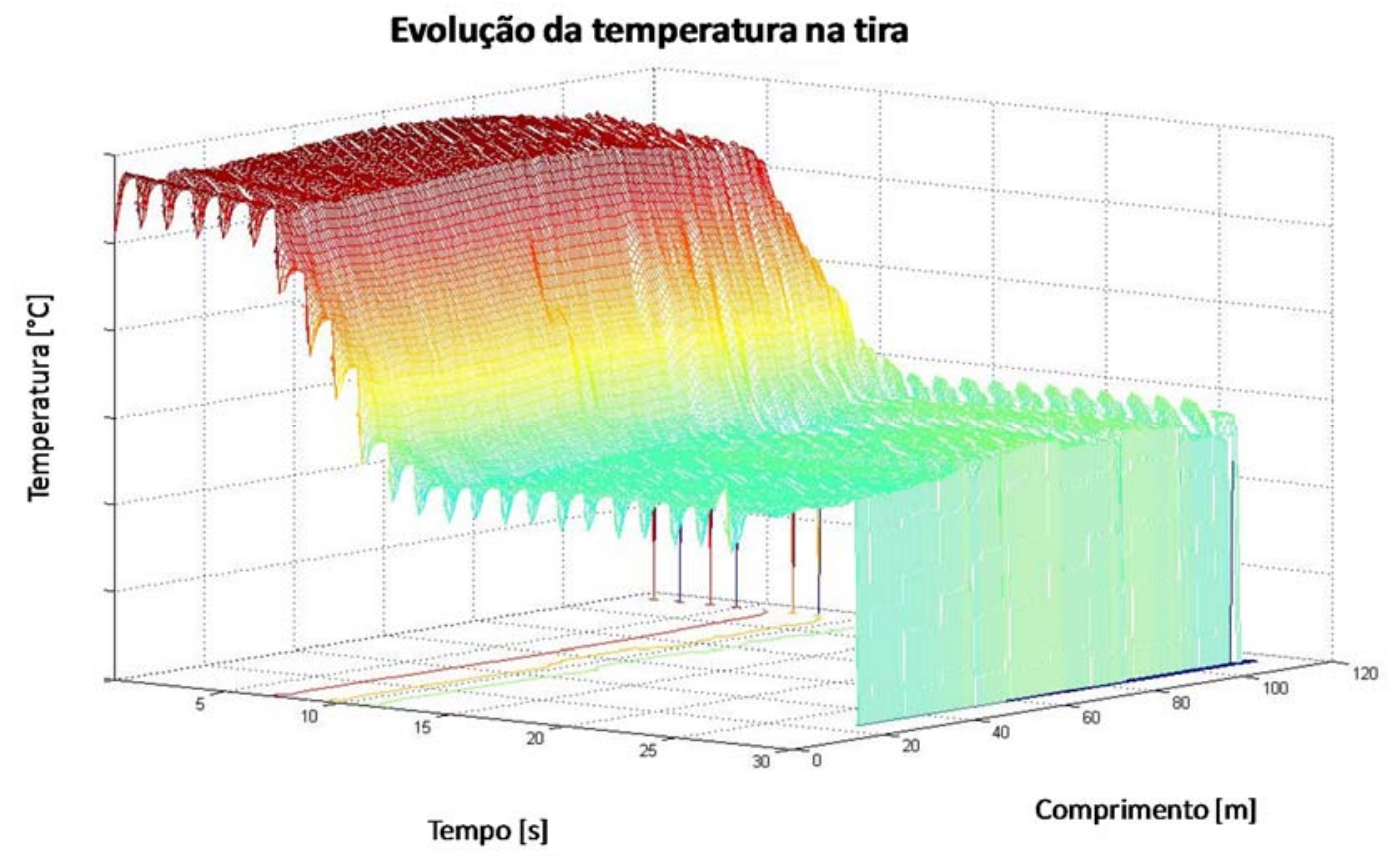

Figura 4. Resfriamento Acelerado 


\subsection{Ensaios Mecânicos}

Os resultados obtidos no ensaio de tração estão sumarizados na Tabela 2. Estão apresentados os valores menores encontrados para LE e LR e os valores médios para razão elástica e alongamento.

Tabela 2. Resultados do Ensaio de Tração

\begin{tabular}{lcccccc}
\hline Espessura & Largura & $\mathrm{L}_{0}$ & LR & $\begin{array}{c}\text { LE } \\
\mathbf{0 , 5 \%}\end{array}$ & $\begin{array}{c}\text { Razão } \\
\text { Elástica }\end{array}$ & Alongamento \\
\hline $9,50 \mathrm{~mm}$ & $37,88 \mathrm{~mm}$ & $50,80 \mathrm{~mm}$ & $549 \mathrm{MPa}$ & $473 \mathrm{MPa}$ & $86 \%$ & $38 \%$ \\
\hline
\end{tabular}

Os valores mínimos de LE e LR especificados na norma API $5 \mathrm{~L}$ para o grau X60 são respectivamente, de $415 \mathrm{MPa}$ e $520 \mathrm{MPa}$ sendo a razão máxima entre estes limites de $93 \%$ [7]. Para o grau $X 65$ os valores especificados para LE e LR são respectivamente $450 \mathrm{MPa}$ e $535 \mathrm{MPa}$. Os resultados obtidos no aço processado atendem com boa margem à especificação do grau X60 e com uma margem de 20MPa à especificação do grau X65.

O alongamento de $38 \%$ é um resultado atrativo no ponto de vista para formabilidade do aço, sendo o aço obtido adequado para fabricação de dutos.

Os resultados dos ensaios de tenacidade ao impacto e do levantamento da curva de transição dúctil frágil estão apresentados na figura 5. Foram efetuados para cada temperatura três ensaios e coletada a média dos valores de energia absorvidos. Foram obtidos resultados de energia de absorvida à temperatura ambiente em torno de 150Joules. Nos ensaios para levantamento da temperatura de transição dúctil frágil a fragilização das amostras ocorreu à temperaturas abaixo de $-50^{\circ} \mathrm{C}$.

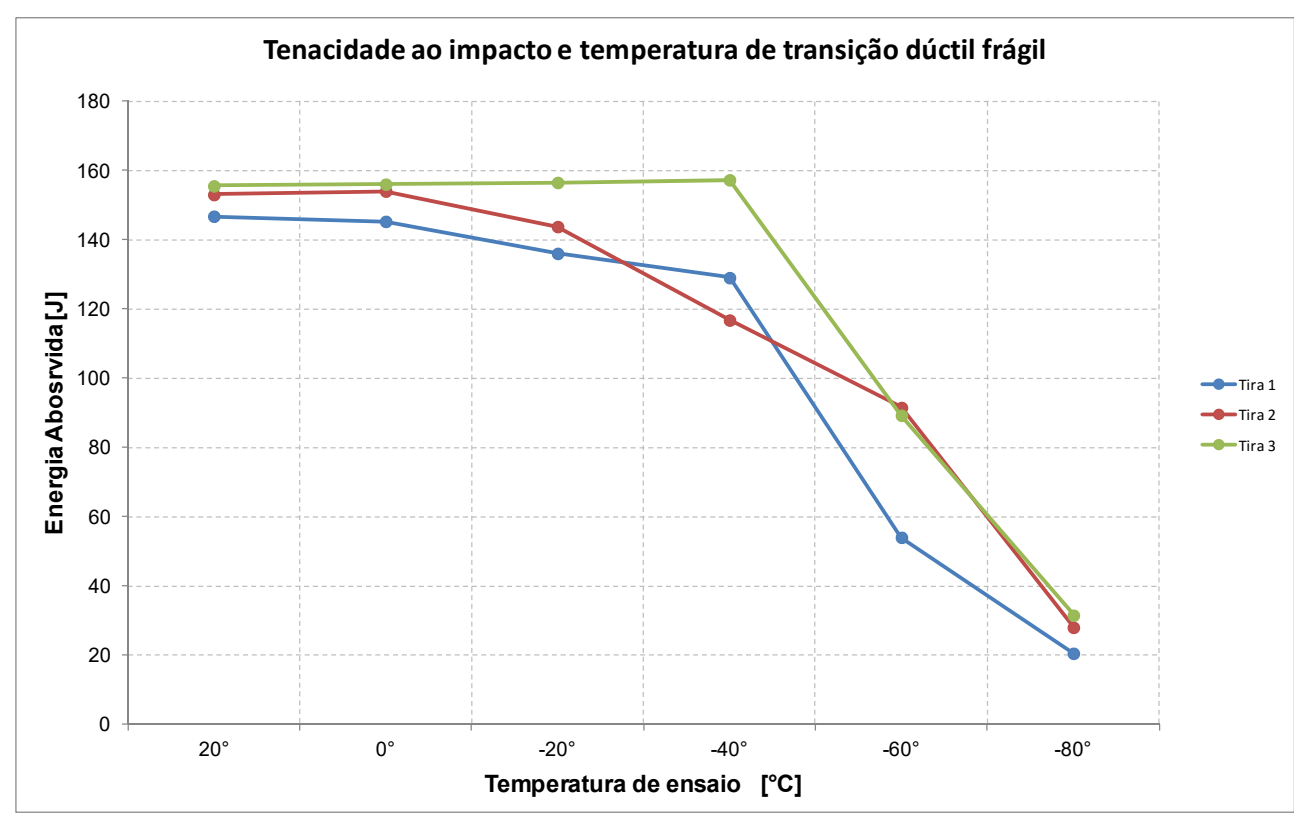

Figura 5. Tenacidade ao impacto e temperatura de transição dúctil frágil

\subsection{Microscopia}

Foram preparadas amostras no laboratório físico químico para análise no Microscópio Ótico e no Microscópio Eletrônico de Varredura. As amostras foram preparadas e atacadas com uma solução de picral $4 \%$ seguido de nital $3 \%$.

Na Figura 6 estão apresentadas as imagens obtidas por microscopia ótica. 

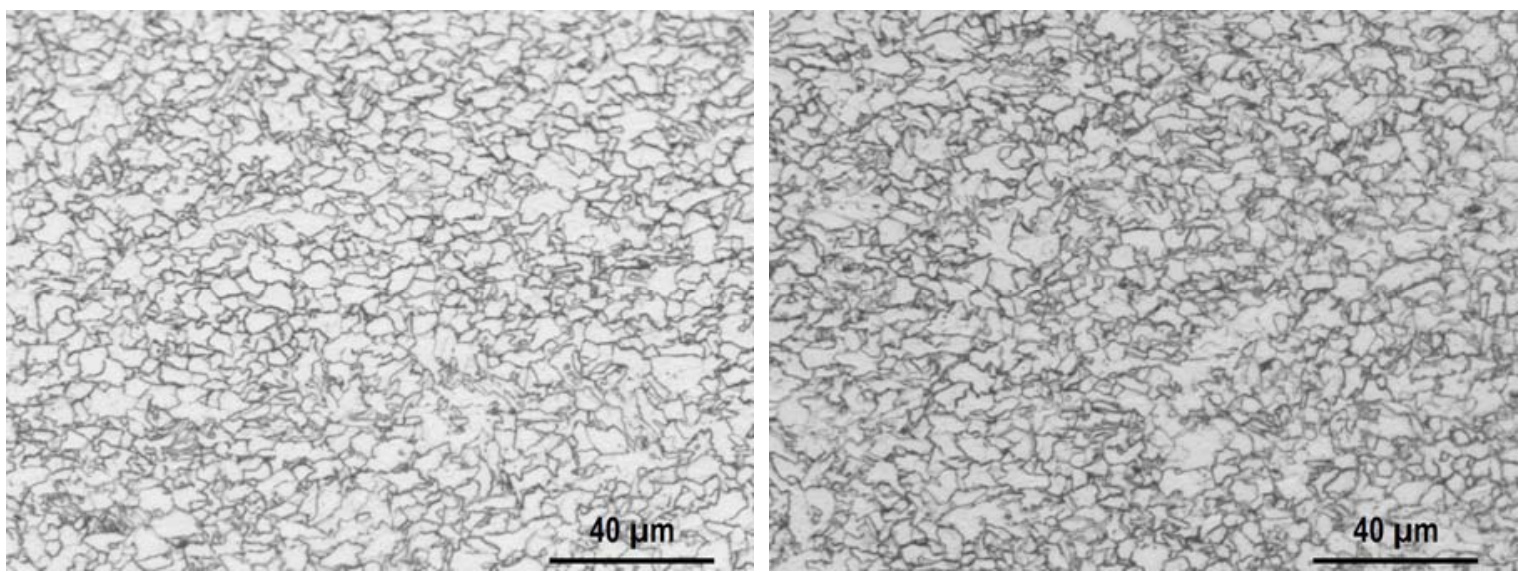

Figura 6. Material com grão ferrítico da ordem de 3,6 $\mu \mathrm{m}$ correspondendo ao número ASTM 13,3

A microestrutura obtida foi composta basicamente de ferrita perlita onde a fração de ferrita em média de $89 \%$ e de perlita $11 \%$. O tamanho médio dos grãos foi de $3,6 \mathrm{~mm}$ ou 13,3 ASTM.

\section{CONCLUSÃO}

Conclui se que por meio de um controle adequado das condições de laminação é possível atingir as propriedades mecânicas desejadas. O principal mecanismo para promoção destas características foi o refinamento de grãos, uma vez que a microestrutura obtida constituiu se de perlita e ferrita basicamente.

A utilização do $\mathrm{Nb}$ como retardador da recristalização do aço se mostrou muito eficiente no estudo realizado, pois foi o único microligante adicionado na liga para tal função.

Os resultados obtidos no presente estudo comprovam que o laminador de tiras a quente tipo Steckel da Gerdau é adequado para produção de aços de alto valor agregado e está equipado com as mais recentes tecnologias para controle dimensional, planicidade e de processo diminuindo assim a possibilidade de desvios por não atendimento às especificações.

\section{REFERÊNCIAS}

1 Miranda L. S. Estudo da Influência de Variáveis de Laminação em uma Linha de Laminação de Tiras a Quente Convencional nas Propriedades Mecânicas de um Aço Alto Nióbio da Classe API 5L X70. Belo Horizonte: Escola de Engenharia da UFMG; 2010

2 Nayak S. S., Misra R. D. K., Hartmann J., Siciliano F., Gray J. M. Microstructure and Properties of Low Manganese and Niobium Containing HIC Pipeline Steel. Materials Science and Engineering A 494; 2008; p. 456-463

3 Yixin H., Yongkuan Y., Daoyuan W., Yuqun Y., Yonglong W., Stalheim D. The Development of High Temperature Processing (HTP) Pipeline Steels at Nanjing Iron and Steel Company, Najing China. Rio Pipeline Conference \& Exposition 2007; 2007

4 Kim K., Effect of Microalloying and Hot Rolling Parameters on Toughness and Yield Strength of API X80 Grade Steel Strips; Fundamentals and Application of Mo and Nb Alloying in High Performance Steels - Volume 1, 2014

5 Gray J. M., Siciliano F. High strength microalloyed pipeline: half a century of evolution. In: 5th International Conference on Pipeline Technology, p. 20-45, Belgium, 2009 
6 Lino J. J. P., Souza A. L., Borges J., Frenn H., Pereira M., Schuwarten W. Os Benefícios da Utilização da Estratégia Tapering na Redução de Cargas nas Pontas da Tira. $51^{\circ}$ Seminário de Laminação - Processos e Produtos Laminados e Revestidos, 2014

7 API Specifications 5L, Specifications for Line Pipe, 44th Edition, American Petroleum Institute, USA, 2007

8 Siciliano Junior, Fúlvio. Mathematical Modeling of the Hot Strip Rolling of $\mathrm{Nb}$ Microalloyed Steels. Doctor of Philosophy thesis, Department of Minning and Metallurgical Engineering, McGill University, Montreal, Canada, 1999

9 Stalheim D., Glodowski R. Fundamentals of the Generation of Fine Grained As-Rolled Structural Steels. Proceedings and Presentation at AIST International Symposium on the Recent Developments in Plate Steels. Winter Park, Colorado USA, Junho 2011

10 Stalheim D. Equations for Rolling Process Design. Comunicação interna. 2016

11 BAI, D. et al. Development of Discrete X80 Line Pipe Plate at SSAB Americas. In: International Symposium on the Recent Developments in Plate Steels, 2011, p. 13-22

12 Santos, A. A. Modelamento da Transformação de Fases de Aços de Alta Resistência Microligados ao Nb Durante o Resfriamento após Laminação em Tiras a Quente. Tese de Doutorado, Departamento de Engenharia Metalúrgica e de Minas, Universidade Federal de Minas Gerais, Belo Horizonte, Brasil, 2007

13 ASTM Designation A370, Standard Test Methods and Definitions for Mechanical Testing of Steel Products, American Society for Testing and Materials, 2014 